\title{
Left ventricular thrombi after acute myocardial infarction
}

\author{
SUDHIR K. BHATNAGAR \\ M.R.C.P.
}

\author{
ABDUL RAZZAK AL YUSUF \\ F.R.C.P.
}

Faculty of Medicine, Kuwait University, Kuwait

\begin{abstract}
Summary
Two-dimensional echocardiography was utilized in a prospective study to find the incidence, characteristics and natural history of left ventricular thrombus in 50 consecutive patients with acute myocardial infarction. The overall incidence of thrombosis was $14 \% ; 19 \%$ in anterior and $5 \%$ in inferior infarction. The thrombus was detected at the apex in 4 , along the ventricular septum in 2 and at both these sites in one patient. It was observed 3-10 days after the infarction.

Thrombus at the ventricular septum, seen in this study, has not been reported previously in acute myocardial infarction. Development of apical and septal thrombi was significantly associated with akinesis of these sites. Only 2 patients with protruding thrombi had systemic embolism.

We conclude that the apex as well as the septum are common sites for thrombosis in patients with severe wall motion abnormalities following acute anterior infarction. Careful observation of these sites during echocardiography may reveal thrombi prone for embolization.
\end{abstract}

KEY WORDS: two-dimensional echocardiography, acute myocardial infarction, ventricular thrombi, arterial embolism.

\section{Introduction}

Left ventricular thrombus is a common complication in congestive cardiomyopathy, ventricular aneurysm and acute myocardial infarction and its features in these conditions have been well described (Ports et al., 1978; Reeder, Tajik and Seward, 1981). Recently, it has been shown that it can be detected noninvasively by platelet imaging (Stratton et al., 1981a), radionuclide angiography (Stratton et al., 1981b) and two-dimensional echocardiography (Ports et al., 1978; Meltzer et al., 1979; De Maria et al., 1979).

Address for reprints: Dr Sudhir K. Bhatnagar, P.O. Box 44294, Hawalli, Kuwait, Arabian Gulf.
Cross-sectional echocardiography has been demonstrated to have predictive accuracy superior even to contrast left ventriculography and is therefore the preferred technique for the recognition of intraventricular thrombi (Reeder et al., 1981).

Information concerning left ventricular thrombus in acute myocardial infarction as compared to other disease states is limited (Asinger et al., 1981a). Therefore, a prospective study of a consecutive group of patients admitted with acute transmural infarction was carried out utilizing two-dimensional echocardiography in order to determine the incidence, characteristics and associations of left ventricular thrombus.

\section{Patients and methods}

Fifty-five consecutive patients admitted to the coronary care unit of Al-Sabah Hospital with acute transmural myocardial infarction for the first time were studied during a 7-month period. There were 52 males and 3 females, aged between 28-70 years. Myocardial infarction was diagnosed on the basis of typical prolonged cardiac pain, evolution of electrocardiographic changes and serial elevation in cardiac enzymes; total creatine kinase (CK), serum glutamic oxaloacetic transaminase (SGOT) and lactate dehydrogenase (LDH).

Patients were not routinely anticoagulated and did not receive any anti-arrhythmic therapy unless necessary. A routine 12-lead electrocardiogram was performed on admission and twice daily for the first $\mathbf{7 2}$ hr.

The initial echocardiographic study was performed within $36 \mathrm{hr}$ of admission and serially on day 3 and day 10 (day 0 defined as the day of admission) in all patients. Assessment of cardiac failure was made according to the Killip classification (Killip and Kimbell, 1967) on day 0, 3 and 10. Two-dimensional echocardiographic study was performed using a commercially available phased array system (Irex III). A $2.25 \mathrm{mHz}, 32$ element focussed transducer with a sector scan of $80^{\circ}$ was used. Real time images were recorded on half-inch video tape using a Sony 
TABLE 1. Clinical characteristics of patients with acute myocardial infarction

\begin{tabular}{|c|c|c|c|c|}
\hline \multirow[b]{2}{*}{ Characteristic } & \multicolumn{2}{|c|}{$\begin{array}{c}\text { Group A } \\
\text { (No thrombus) }\end{array}$} & \multicolumn{2}{|c|}{$\begin{array}{c}\text { Group B } \\
\text { (Thrombus present) }\end{array}$} \\
\hline & Anterior infarction & Inferior infarction & Anterior infarction & Inferior infarction \\
\hline Number of patients & 25 & 18 & 6 & 1 \\
\hline $\begin{array}{l}\text { Age (years) } \\
\text { (range) }\end{array}$ & $\begin{array}{c}49 \pm 10 \\
(28-70)\end{array}$ & $\begin{array}{c}52 \pm 10 \\
(29-67)\end{array}$ & $\begin{array}{c}49 \pm 16 \\
(29-70)\end{array}$ & 65 \\
\hline Killip class & $1.4 \pm 0.7$ & $1 \cdot 1 \pm 0 \cdot 3$ & $1 \cdot 7 \pm 0.5$ & 1 \\
\hline Peak CK(IU/l) & $1409 \pm 949$ & $1246 \pm 874$ & $2065 \pm 1439$ & 1050 \\
\hline Peak SGOT(IU/l) & $244 \pm 155$ & $190 \pm 80$ & $410 \pm 162$ & 259 \\
\hline Peak LDH(IU/l) & $826 \pm 391$ & $612 \pm 209$ & $716 \pm 197$ & 750 \\
\hline
\end{tabular}

Values are mean \pm s.d. The enzyme values are the highest obtained and the Killip class the worst score.

Betamax cassette recorder. These images were then available for redisplay and evaluation in real-time, slow motion or single frame format. A systematic examination was made utilizing parasternal long axis view, short axis views at the mitral valve and papillary muscle levels and apical 2 and 4 chamber views (Tajik et al., 1978). Apical views were obtained utilizing shallow depth of field settings of 7.5 or 10 $\mathrm{cm}$, in order to avoid near field artifacts and were most useful in studying the left ventricular apex for wall motion abnormalities and thrombi (Asinger et al., 1981b).

Ventricular thrombosis was diagnosed when an echo dense mass in the left ventricle, that had distinct margins clearly delineated from the underlying myocardium and endocardial echo was seen, associated with a wall motion abnormality (Meltzer $e$ t al., 1979; Asinger et al., 1981b). Agreement of 2 independent observers was required for the diagnosis of thrombosis. When the thrombus was noticed, echocardiographic examination was repeated at 3-day intervals during hospitalization and at fortnightly intervals after discharge of the patient.

Apical and septal wall motion was analyzed visually utilizing all the echocardiographic views and classified as normal, hypokinetic and akinetic (Asinger et al., 1981a).

All patients had at least 3 echocardiograms. Five patients were excluded from the study because of unsatisfactory echocardiograms. The remaining 50 patients were divided into 2 groups, depending on the absence (Group A) or presence (Group B) of ventricular thrombus (Table 1).

\section{Statistical methods}

Values for clinical and enzymatic observations were expressed as mean \pm standard deviation. Comparisons in the clinical groups were made by the median values using chi-square test or Mann-Whido ney test. The incidence of left ventricular thrombosis in the clinical groups was tested by the 'test significance between two proportions'. Differences were considered significant if $P$ was $<0.05$.

\section{Results}

The overall incidence of left ventricular thronis $\vec{\circ}$ sis was found to be $14 \%$ ( 7 of 50); $19 \%$ (6 of 3 . patients with anterior and $5 \%(1$ of 19$)$ in patiênts with inferior infarction (difference not statistically significant).

Clinical characteristics of the patients studied ane shown in Table 1. The average worst Killip class di not differ significantly between patients with anteriog infarction with or without thrombi. Among the enzymes, only the peak SGOT values were signifcantly higher in group B patients compared wi patients in group $A(P<0.05)$. As there was only one patient with inferior infarction in group $B$, no comparison was made between this and inferier infarct patients in group $A$.

The features of 7 patients with a definite thrombis (Group B) are shown in Table 2. The thrombus was detected at the left ventricular apex alone in of patients (example Fig. 1 and 3), along the ventriculăr septum in 2 patients (example, Fig. 4) and in one patient a mobile, protruding thrombus, in addition tô an apical thrombus, was noticed at the septum neag the left ventricular outflow tract (Fig. 2). Contrast lef ventriculography confirmed the presence of apich thrombus in one patient (case 1) 150 days later.

The thrombus was detected in 6 patients by the third day and, in only one case, it was detected on the tenth day. Two patients died, the thrombus resolved in 3 between 20-180 days and was still present in the other 2 at day 60 and 150 respectively. 
TABLE 2. Clinical and echocardiographic features of patients with left ventricular thrombus (Group B)

\begin{tabular}{|c|c|c|c|c|c|c|c|c|}
\hline Case & Site of infarct & LVT site & $\begin{array}{c}\text { LVT } \\
\text { length } \\
(\mathrm{cm})\end{array}$ & $\begin{array}{l}\text { Type of } \\
\text { LVT }\end{array}$ & $\begin{array}{l}\text { Wall motion } \\
\text { at LVT site }\end{array}$ & $\begin{array}{c}\text { Day } \\
\text { appeared }\end{array}$ & $\begin{array}{l}\text { Resolution/time taken } \\
\text { (days) }\end{array}$ & $\begin{array}{c}\text { Anti- } \\
\text { coagulation* }\end{array}$ \\
\hline \multirow[t]{2}{*}{1} & Anterior & (1) Septum & $1 \cdot 5$ & $P \ddagger$ & A & 10 & Yes $/ 20$ & \\
\hline & & (2) Apex & 3 & M & A & 10 & Yes/180 & + \\
\hline$\dagger 2$ & Anterior & Apex & $1 \cdot 5$ & $P \ddagger$ & $\mathbf{A}$ & 3 & No/- & + \\
\hline 3 & Anterior & Septum & 3 & $\mathbf{M}$ & A & 3 & No/150 & - \\
\hline$\dagger 4$ & Anterior & Apex & 1 & $\mathbf{M}$ & A & 3 & No/- & + \\
\hline 5 & Inferolateral & Septum & 2 & $\mathbf{M}$ & $\mathbf{H}$ & 3 & Yes/60 & - \\
\hline 6 & Anterior & Apex & 1.5 & $\mathbf{M}$ & A & 3 & No/60 & + \\
\hline 7 & Anterior & Apex & 1.5 & $\mathbf{M}$ & A & 3 & Yes $/ 25$ & + \\
\hline
\end{tabular}

Abbreviations: $\mathbf{L V T}=$ left ventricular thrombus; $\mathbf{M}=$ mural; $\mathrm{P}=$ protruding; $\mathrm{A}=$ akinesis; $\mathrm{H}=$ hypokinesis.

*commenced after thrombus detection; †Died; $¥$ Systemic embolism.

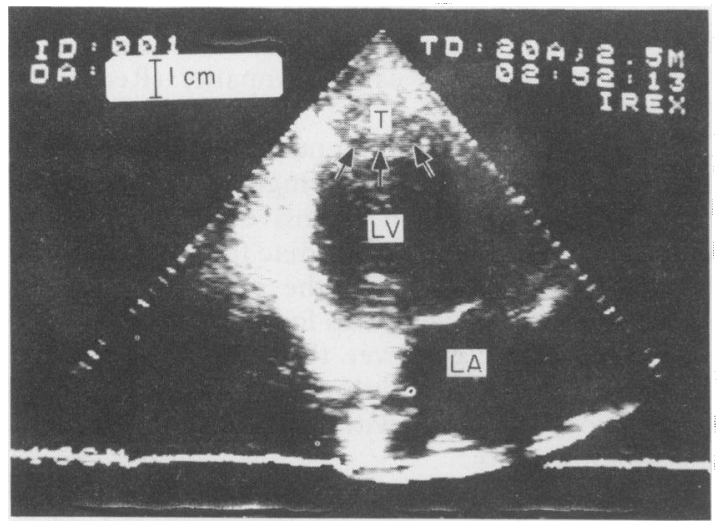

FIG. 1. Apical two-chamber view (Case 6). Arrows denote thrombus (T) at the apex. $L V=$ Left ventricle; $L A=$ Left Atrium.

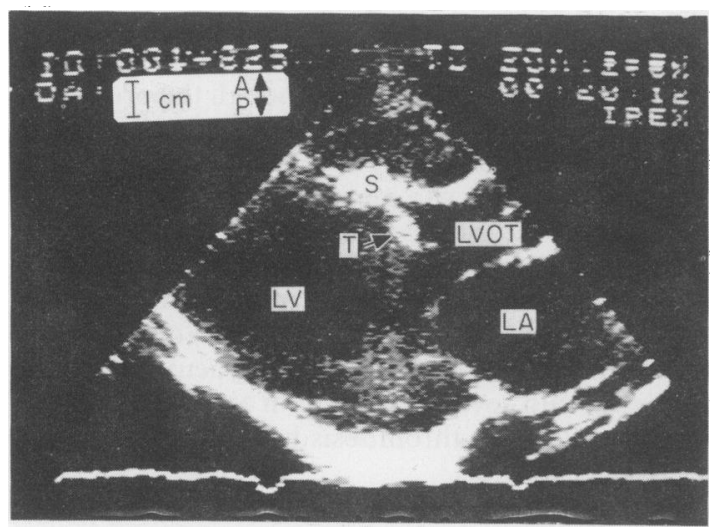

FIG. 2. Parasternal long axis view (Case 1). Protruding thrombus (arrow) along the ventricular septum (S) near the LV outflow tract (LVOT) $\mathrm{A}=$ Anterior; $\mathrm{P}=$ Posterior; other abbreviations as in Fig. 1.

Clinical systemic embolism occurred in 2 patients within 10 days of the infarct and only these 2 patients had protruding thrombi.

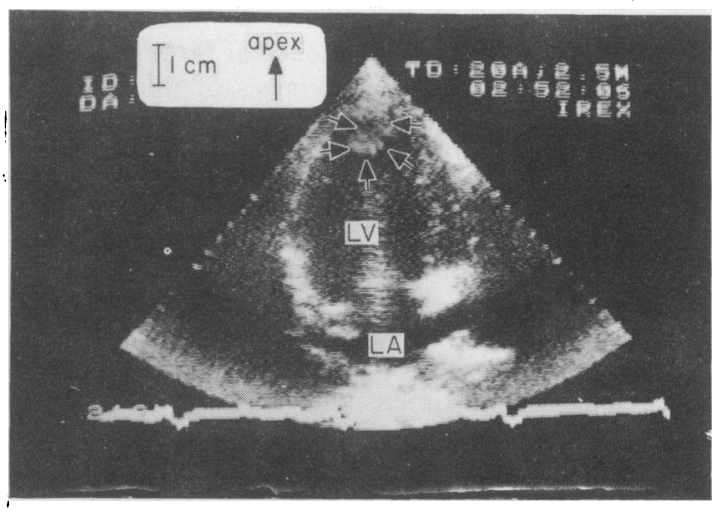

Fig. 3. Apical view (Case 2). Protruding thrombus (arrows) at the apex. Other abbreviations as in previous figures.

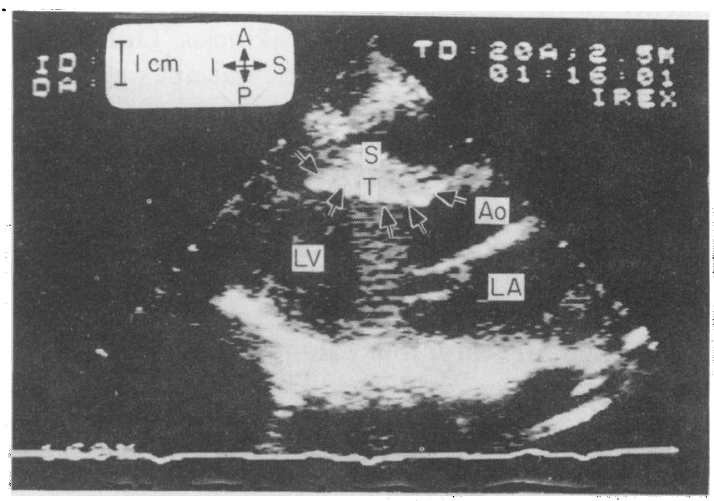

FiG. 4. Parasternal long axis view (Case 3). Mural thrombus (arrows) at the septum (S); $A o=$ aorta; $I=$ inferior; $S=$ superior; other abbreviations as in previous figures.

\section{Echocardiographic wall motion analysis}

Analysis of apical wall motion at the time of initial study in the 2 groups is shown in Table 3. This remained unchanged in the subsequent studies. The incidence of thrombosis at the apex in patients with 
TABLE 3. Comparison of apical and septal wall motion in patients with and without left-ventricular thrombi

\begin{tabular}{|c|c|c|c|c|c|c|c|c|}
\hline \multirow[b]{3}{*}{ Type of wall motion } & \multicolumn{8}{|c|}{ Number of patients } \\
\hline & \multicolumn{4}{|c|}{ Group A (No thrombus) } & \multicolumn{4}{|c|}{ Group B (Thrombus +) } \\
\hline & \multicolumn{2}{|c|}{$\begin{array}{l}\text { Anterior infarction } \\
\text { (Apex) }\end{array}$} & \multicolumn{2}{|c|}{$\begin{array}{l}\text { Inferior infarction } \\
\text { (Apex) } \\
\text { (Septum) }\end{array}$} & \multicolumn{2}{|c|}{ Anterior infarction } & \multicolumn{2}{|c|}{$\begin{array}{c}\text { Inferior infarction } \\
\text { (Apex) }\end{array}$} \\
\hline Normal & 3 & 9 & 14 & 18 & 0 & 0 & 0 & 0 \\
\hline Hypokinesis & 7 & 10 & 2 & 0 & 0 & 4 & 1 & $1^{*}$ \\
\hline Akinesis & 15 & 6 & 2 & 0 & $6+$ & $2 *$ & 0 & 0 \\
\hline
\end{tabular}

apical akinesis (both groups combined) was $22 \%$ ( 5 of 23) and the presence of thrombus at this site was significantly associated with apical akinesis by chisquare test $(P<0.05)$. The incidence of thrombosis at the septum in patients with akinesis of this region (both groups combined) was 25\% (2 of 8 ) and its occurrence at this site was also significantly associated with akinetic septum by chi-square test $(P<0.01)$.

\section{Discussion}

The overall incidence of left ventricular thrombosis detected by two-dimensional echocardiography, following acute transmural myocardial infarction in this study was $14 \%$, similar to the incidence in a recent report (Asinger et al., 1981a), although in autopsy studies this has been reported to vary from $38 \%$ (Jordan et al., 1952) to 67\% (Garvin, 1941). The incidence of thrombosis at the left ventricular apex was $22 \%$ in patients with apical akinesis. Our data indicates that akinesis of the ventricular apex predisposes to thrombus formation at this site, a finding that is in agreement with the observation of Asinger et al., (1981a). We also observed a higher incidence of ventricular thrombosis in anterior than in inferior infarction, although this difference did not reach statistical significance.

An unusual observation in the present study was the presence of thrombus along the ventricular septum in 3 of the 7 patients. This finding has not been previously described in association with acute myocardial infarction. In previous reports however, septal thrombi have been noticed with cardiomyopathy and left ventricular aneurysm (Reeder et al., 1981).

Protruding thrombi with free intracavitary motion of their margins were noted to have a high risk of embolization, as both patients with this type of thrombus were the only patients who had clinical systemic embolism. This observation confirms other reports (De Maria et al., 1979; Haugland et al., 1981). Whether anticoagulation will prevent embolism in such patients will have to be determined by prospec- tive studies, but presently it appears prudent anticoagulate such patients.

The size of the thrombi in our patients was sma unlike the large mural thrombi that are more common in congestive cardiomyopathy (Reeder $\mathscr{e}$ al., 1981).

Previous autopsy studies in patients dying of acute infarction have reported a higher incidence of ventricular thrombosis in extensive anterior infaretion and in the presence of cardiac failure (Jordan et al., 1952; Garvin, 1941). In the present study, the majority of thrombi were also found in patients wi anterior infarction. However, there was no differenge in the severity of cardiac failure assessed by the Killip classification, in patients with anterior infarction 8 or without thrombi.

It is interesting to note that thrombi were seen 8 nty at the apex and the septum in this series and aiog the inferior wall in only one other report (Asinger हैt al., 1981b). Focal stasis of intracavitary blood to gether with endocardial injury seem to be necessagy for the development of thrombus (Jordan et al., 1952) and it is probably due to these factors that thrombins tends to develop at the apex. Although the predisposing factors for the development of septal thrombi our patients are not clear, it appears from our dafa that akinesis of this site plays a major role.

Our results indicate that although the left ventricilar apex is the most common site for thromboșis following acute myocardial infarction, the ventricislar septum may also be involved. Whether eary short-term anticoagulation following acute infarction in patients with severe wall motion abnormalities can prevent ventricular thrombosis has to be determined by prospective trials.

\section{References}

Asinger, R.W., Mikell, F.L., Elsperger, J. \& Hodges, (1981a) Incidence of left-ventricular thrombosis after acufe transmural myocardial infarction: serial evaluation by twodimensional echocardiography. New England Journal of Mediciffe, 305, 297.

Asinger, R.W., Mikell, F.L., Sharma, B. \& Hodges, M. (19816) Observations on detecting left ventricular thrombus with tकo 
dimensional echocardiography: emphasis on avoidance of false positive diagnosis. American Journal of Cardiology, 47, 145.

GAR VIN, C.F. (1941) Mural thrombi in the heart. American Heart Journal, 21, 713.

Haugland, J.M., Asinger, R.W., Mikell, F.L., Elsperger, K.J. \& Hodges, M. (1981) Embolic potential of left ventricular thrombus (LVT) detected by two-dimensional echocardiography (2DE). (abstract) American Journal of Cardiology, 47, 471.

JoRdAN, R.A., Miller, R.D., EdWARDS, J.E. \& PARKer, R.L. (1952) Thrombo-embolism in acute and in healed myocardial infarction. Circulation, 6, 1.

KILLIP, T. III \& KIMBELL, J.T. (1967) Treatment of myocardial infarction in a coronary care unit: a two year experience with 250 patients. American Journal of Cardiology, 20, 457.

Maria, A.N. De, Bommer, W., Neumann, A., Grehl, T., WeinART, L., NARDO, S. DE, AMSTERDAM, E.A. \& MASON, D.T. (1979) Left ventricular thrombi identified by cross-sectional echocardiography. Annals of Internal Medicine, 90, 14.

Meltzer, R.S., Guthaner, D., Rakowski, H., Popp, 'R.L. \& MARTIN, R.P. (1979) Diagnosis of left ventricular thrombi by twodimensional echocardiography. British Heart Journal, 42, 261.
Ports, T.A., Cogan, J., Schiller, N.B. \& Rapaport, E. (1978) Echocardiography of left ventricular masses. Circulation, 58, 528.

REEDER, G.S., TAJIK, A.J. \& SEWARD, J.B. (1981) Left ventricular mural thrombus - two dimensional echocardiographic diagnosis. Proceeding, Mayo Clinic, 56, 82.

Stratton, J.R., Ritchie, J.L., Hamilton, G.W., HammerMEISTER, K.E. \& HARKER, L.A. (1981a) Left ventricular thrombi: in vivo detection by Indium-III platelet imaging and two dimensional echocardiography. American Journal of Cardiology, 47, 874.

STRATTON, J.R., RITCHIE, J.L., H.AMMERMEISTER, K.E., KENNEDY, J.W. \& HAMilton, G.W. (1981b) Detection of left ventricular thrombi with radionuclide angiography. American Journal of Cardiology, 48, 565.

TAJIK, A.J., SEward, J.B., Hagler, D.J., MaIR, D.D. \& Lie, J.T. (1978) Two-dimensional real-time ultrasonic imaging of the heart and great vessels: technique, image orientation, structure identifcation and validation. Proceedings, Mayo Clinic, 53, 271.

(Accepted 17 February 1983) 